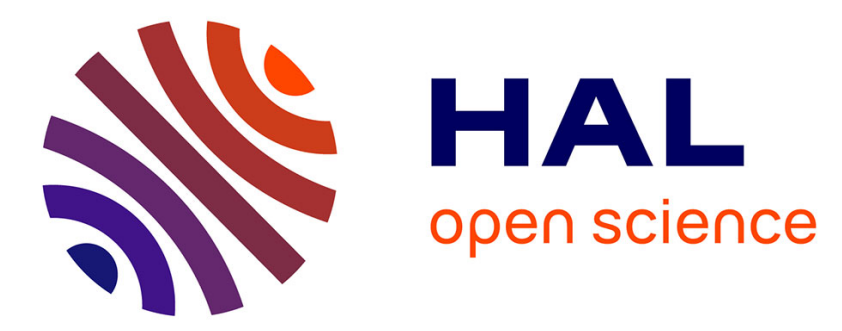

\title{
Using Underwater Imagery as a Complementary Tool for Benthos Sampling in an Area with High-Energy Hydrodynamic Conditions
}

Aurélie Foveau, Sylvain Haquin, Jean-Claude Dauvin

\section{To cite this version:}

Aurélie Foveau, Sylvain Haquin, Jean-Claude Dauvin. Using Underwater Imagery as a Complementary Tool for Benthos Sampling in an Area with High-Energy Hydrodynamic Conditions. Journal of Marine Biology \& Oceanography, 2017, 06 (02), 10.4172/2324-8661.1000177 . hal-02060500

HAL Id: hal-02060500

https://hal-normandie-univ.archives-ouvertes.fr/hal-02060500

Submitted on 7 Mar 2019

HAL is a multi-disciplinary open access archive for the deposit and dissemination of scientific research documents, whether they are published or not. The documents may come from teaching and research institutions in France or abroad, or from public or private research centers.
L'archive ouverte pluridisciplinaire HAL, est destinée au dépôt et à la diffusion de documents scientifiques de niveau recherche, publiés ou non, émanant des établissements d'enseignement et de recherche français ou étrangers, des laboratoires publics ou privés. 


\section{Using Underwater Imagery as a Complementary Tool for Benthos Sampling in an Area with High- Energy Hydrodynamic Conditions} Aurélie Foveau ${ }^{1,2}$, Sylvain Haquin ${ }^{1,3}$ and Jean-Claude Dauvin ${ }^{1 *}$

\begin{abstract}
Underwater imagery is increasingly being used in the description of communities and habitats, as a tool to aid in the designation and management of marine protected areas. Here, we developed an underwater imagery system to monitor the seafloor and benthic communities in the Raz Blanchard (Aldernez Race), an area in the English Channel characterized by high-energy hydrodynamics. Despite the difficult conditions of acquisition, the underwater images highlighted the heterogeneous nature of the seabed in the Raz Blanchard. In this way, underwater imagery is a useful tool in providing additional information to standard benthic observations, particularly for the description of sessile epifauna and benthic landscapes. This system is flexible, robust and simple enough to be used in coastal and offshore areas, and is suitable as a complementary tool in benthic surveys to monitor the status and changing trends of seabed fauna and could be applied in future surveys.
\end{abstract}

\section{Keywords}

Underwater imagery; Sampling; Benthos; English Channel; Hard bottoms

\section{Introduction}

The first application of the use of underwater photography for scientific purposes is often attributed to Louis Boutan in 1893 [1]. However, the real expansion of underwater imagery took place in the middle of the 20th century [2,3]. Reductions in cost and the development of high-definition photography led to the use of these non-destructive techniques in many fields, from habitat description to fisheries, including benthic studies [3-7] and distribution of epibenthic assemblages or the overall biodiversity of an area [8-10]. Typical applications of underwater imagery include evaluation of the size and population densities of exploited benthic species, such as shellfish and crustaceans [5,11,12]. Many techniques have been developed to account for highly mobile species, but the preferred approaches involve remotely operated vehicles (ROVs) or towed camera systems. These techniques also allow the study of benthosfish associations [13-15]. The intensification of human pressures on natural marine resources has increased the demand for impact studies before new activities such as aggregate extractions and marine

*Corresponding author: Jean-Claude Dauvin, Normandie Univ., UNICAEN, UNIROUEN, Université de Caen Normandie, Laboratoire de Morphodynamique Continentale et Côtière, UMR CNRS 6143 M2C, 24 rue des Tilleuls, F-14000 Caen, France, Tel: +33-231565722; E-mail: jean-claude.dauvin@unicaen.fr

Received: July 05, 2017 Accepted: August 04, 2017 Published: August 11, 2017 10 renewable energy developments. Moreover, the effects on vulnerable marine ecosystems have now become an international concern [6]. As a result, underwater imagery could be used for mapping and quantifying indicators of human pressures on marine habitats such as marine debris, lost fishing gear, traces of bottom trawling or dredging [6,16-18].

Underwater imagery is considered as a non-destructive sampling tool. But this tool also provides valuable feedback regarding the identification of good environmental status in the context of the Marine Strategy Framework Directive 2008/56/EC of 17 June 2008, which covers such aspects as: (1) biodiversity, (2) non-indigenous species, (3) commercial fish and shellfish, (6) sea-floor integrity, (7) hydrographical conditions and (10) marine litter. Underwater imagery techniques can also be used in the monitoring and development of indicators on the status and functioning of ecosystems [19].

For these different applications, it is possible to use dropped systems (drop-type camera), operable on small surface areas, or towed camera systems, operable along transects [6]. Dropped systems often have a small spatial coverage, making them difficult to use to monitor mobile species.

Underwater imagery is taken here as referring to sampling by photos and videos. Moreover, underwater imagery yields visual material that is appreciated even by a non-specialist public. Similarities may be established between underwater imagery and biological sampling data. As is the case with benthic samples, the data treatment and analysis of images varies depending on the requirements. Nevertheless, numerical images may be treated and analysed without destruction of the sample, and can be used for various purposes that are different from those that have led to the acquisition. Underwater imagery often yields a snapshot of the status of an area (or habitat) at a given time, thus establishing a benchmark or baseline reference. It is considered that underwater imagery offers a number of advantages over conventional benthic sampling.

Few benthic studies were conducted in the Alderney Race. The historical study was conducted by Retière [20], and involved some stations in the Alderney Race. More recently, Broadhurst [21] made some surveys in the Alderney Channel Islands waters with collection of benthic samplings and underwater imagery. These studies were made on the boundaries of the Alderney Race, where the environmental conditions are already more promising. Our study is the first with collection of benthic samplings and images of the ecosystem, directly in the heart of the Alderney Race, where the conditions are rough.

In the present study, we attempt to describe the development of an underwater imagery system to monitor the seafloor and benthic communities in an area with high-energy hydrodynamics. Our system supplements the standard benthic sampling in the Raz Blanchard, in the western basin of the English Channel between Alderney (Channel Islands, UK) and the Cap de La Hague (Normandy, France) which is carried out with a Rallier du Baty dredge, as sampling by grabs is impossible.

\section{Materials and Methods}

\section{Sledge characteristics}

The sledge developed here belongs to the "towed system" category. It is a benthic sledge with two contact runners, designed to

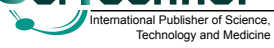


Citation: Foveau A, Haquin S, Dauvin J (2017) Using Underwater Imagery as a Complementary Tool for Benthos Sampling in an Area with High-Energy Hydrodynamic Conditions. J Mar Biol Oceanogr 6:2.

withstand the different types of sea conditions, currents and depth ranges encountered in the English Channel $(0-175 \mathrm{~m})$. It also has to be easily operable so that non-specialist staff can use it, but not too large to be deployed from relatively small research vessels or monitoring crafts $(15-25 \mathrm{~m})$. The sledge is able to survey a range of habitats from small boulders and pebbles to mud, but may also be used on bedrock and large boulder field. The system has no communication link with the surface and only requires a towing rope or cable to be operated. Its design is based on a previous "Troika" model used by the Caen laboratory and also on systems employed during the PANACHE project (Protected Area Network Across the Channel Ecosystem, project INTEREG IV A) [7] as well as the MPO sledge (Ministère Pêches et Océans, Canada) [5].

The dimensions are as follows: $1.7 \mathrm{~m}$ (length without tow bar. 3 $\mathrm{m}$ with it) $\times 1 \mathrm{~m}$ (height) $\times 1.215 \mathrm{~m}$ (width), with a weight of $225 \mathrm{~kg}$ (Figure 1). The frame is made from stainless steel (Figure 2A). At sea, the frame is weighted by lead to $50 \mathrm{~kg}$ to ensure stability to the camera. Moreover, during tests at sea, it was noted that the fitting of floats at the front of the frame helped to ensure correct immersion (Figure 2B).

The 'Troika' frame itself was assembled by qualified welders. All the other equipment were bought in mainstream shops but specialised in their domain. The final assemblage of the whole system was done with the oceanographer technician of our laboratory. These choices allow to (1) reduce the cost of the system, and (2) change it quickly or repair it more easily if it breaks.

\section{Optic systems}

The camera objective is situated about $60 \mathrm{~cm}$ above the seabed (there is no contact of the camera with the seabed), which is close enough to identify many mega-epibenthic and macro-epibenthic species under varying visibility conditions, while still offering a large enough field of view for habitat description. The camera system comprises anodized aluminium housing with a depth rating of 130 m (Aquatica) able to contain a D810 Nikon camera. The camera is equipped with a lens with a fixed focal of $35 \mathrm{~mm}$ and positioned perpendicularly to the horizontal plane. The angular cover is about $32.1^{\circ}$ in the water that allows it to obtain images presenting little spherical distortion and on which there is no significant difference of sharpness between the margins and the centre of the image. The "useful" resolution, obtained by the assembly on the sledge, allows to identify elements as small as approximately $2 \mathrm{~mm}$.

One flash unit is installed on each side of the camera, with an appropriate converging angle targeting the photographed area. A forward Go-Pro video camera is attached to the back of the Nikon camera, at an angle of $20^{\circ}$, to film the seafloor and assess the benthic landscape and mobile species. One LED light (underwater LED Bersub ${ }^{\circ}$ HD PRO $12+$ NEUTRAL) is fixed in parallel to the Go-Pro at an appropriate angle to cover the entire field of view of the video camera.

\section{Calibration of the system}

The images are taken with a fixed focus. Other parameters are also

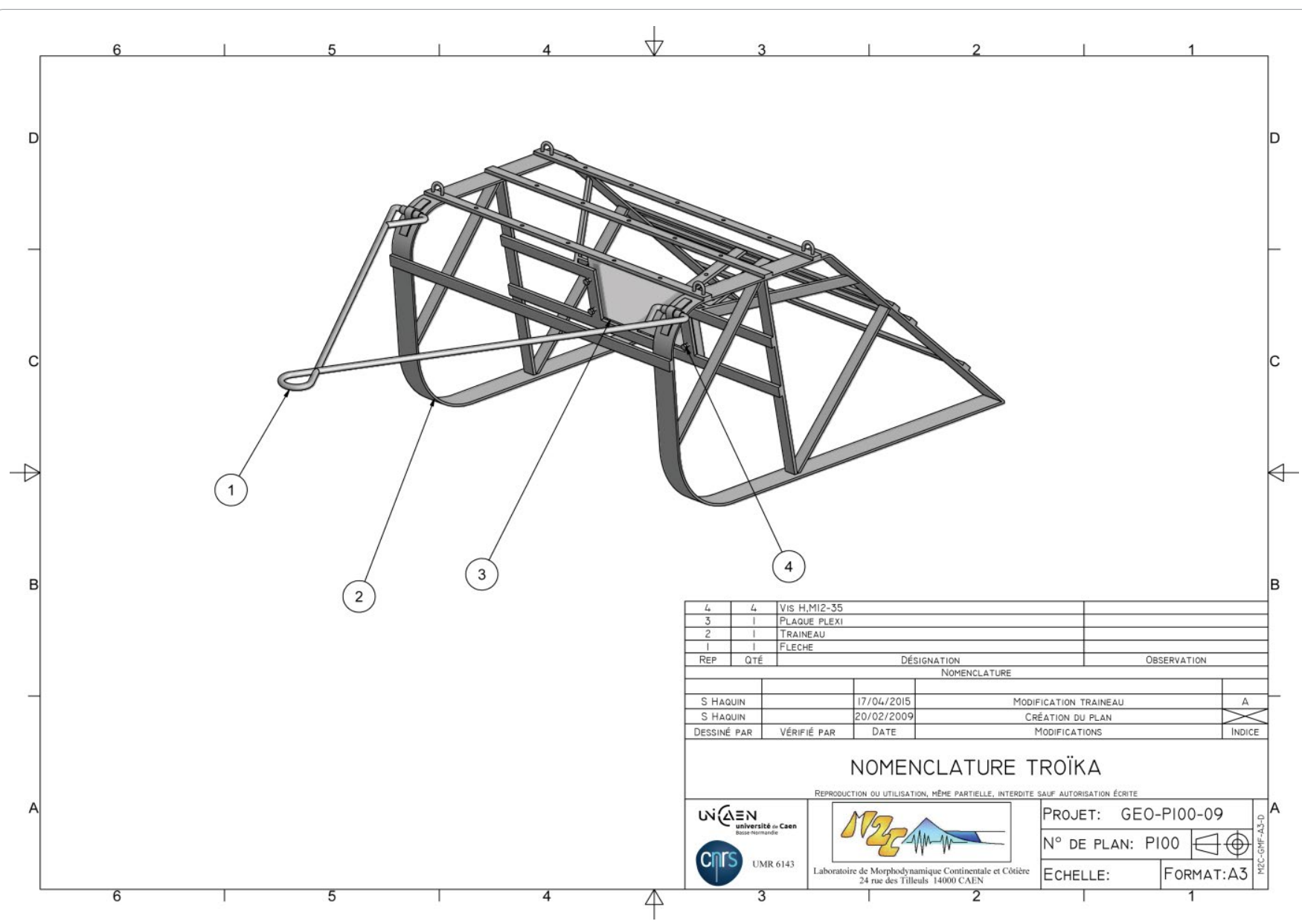

Figure 1: Design of the sledge. 
Citation: Foveau A, Haquin S, Dauvin J (2017) Using Underwater Imagery as a Complementary Tool for Benthos Sampling in an Area with High-Energy Hydrodynamic Conditions. J Mar Biol Oceanogr 6:2.

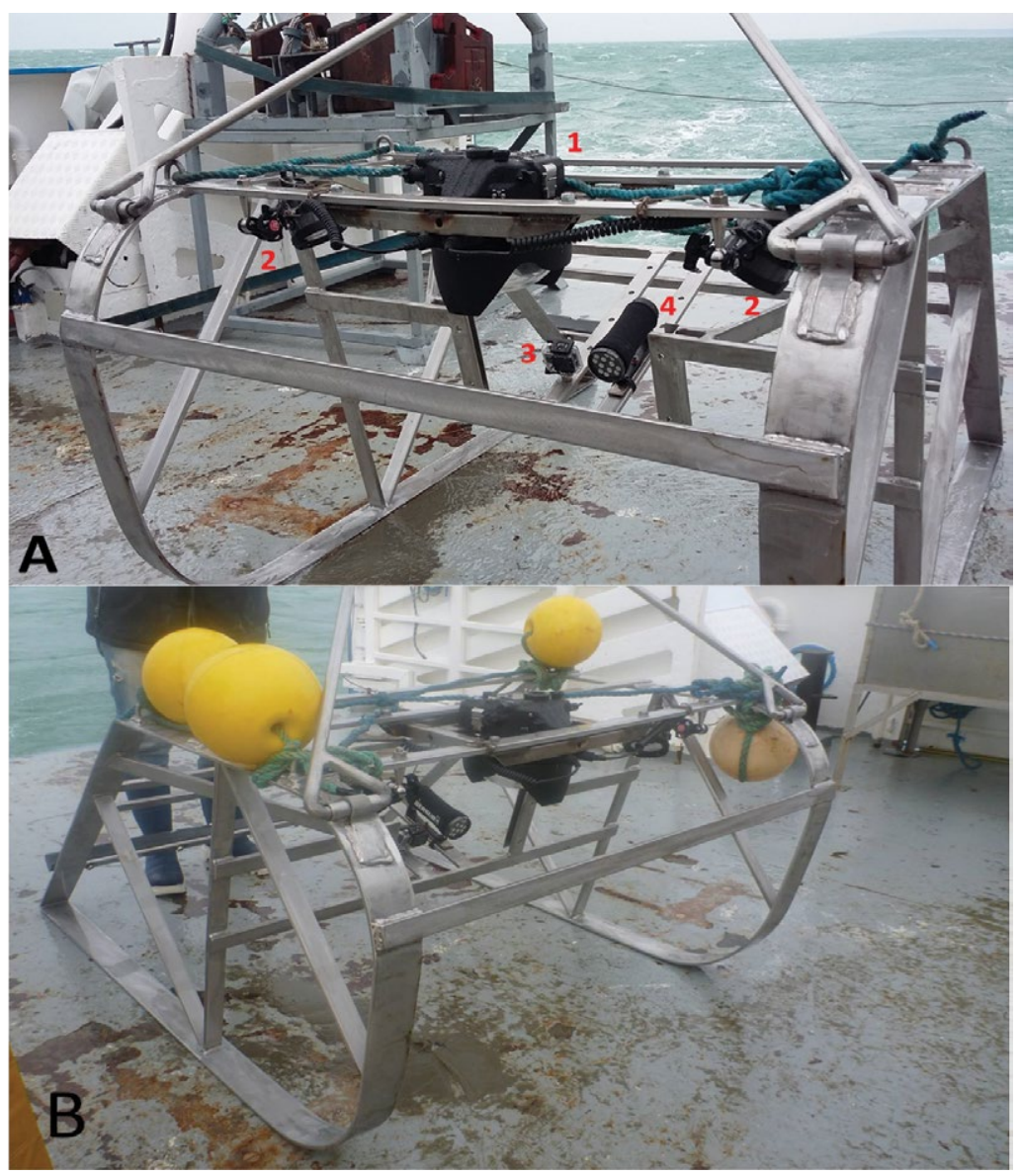

Figure 2: Underwater imagery sledge and on-board equipment: A (1) camera in sealed housing, (2) flash unit, (3) Go-Pro movie camera in sealed housing and (4) LED; B with floats.

fixed (opening: $\mathrm{f} / 13$, shutter speed: $1 / 125$ second, sensibility: iso 100 ) and was established according to the distance of the subject and the intensity of the lighting.

The camera system was calibrated in pond. In order to test the field covered by the camera and the image sharpness, images of a submerged grid were taken. The surface covered by an image is 0.13 $\mathrm{m}^{2}$ at the distance and the focus given above. This calibration helps us later to measure the fauna if needed.

\section{Images acquisition}

Before deploying the sledge at sea, a bathymetric cover of the studied area was made by using the sonar of the vessel. We only retained flattest areas, without high variations of the seabed to avoid impacts on the sledge.

The sledge was launched with a winch. Coordinates, depth and the length of deployed cable were noted at the beginning and at the end of every transect. If depth suddenly changed, the length of the cable was adjusted. Photos are taken by using the interval drive mode to specify the duration of the interval between shots, which is set here at 15 seconds.

\section{Photos analyses}

After their acquisition, the photos are imported, from the SD card, into a digital index on the type of Lightroom, in a native and jpeg formats, where they are labelled with tags allowing classification of the images (acquisition date, survey and dominant species). If required, the images can be enhanced before being analysed.

According to the number of images taken by transect, it is possible to select the images to be analysed (Table 1). A processing sampling step is fixed by transect, which is then applied to each image in a sequence of five (the selection of images beginning with the first sequence acquired on the bottom). If the selected image is not interpretable (failure of the flash, excessive turbidity, sharpness, etc.), the next image in the sequence is selected. Then, the initial sequence is recovered.

Videos are mainly used to note the presence (or absence) of certain characteristics of the environment or for counting large-sized and/or very mobile organisms. Acquisitions of the results from the pictures are made with ImageJ freeware.

\section{Study area and survey}

The Raz Blanchard (Alderney Race in English) is located in the western part of the English Channel to the North of the Normand-Breton Gulf, lying between the French coast on the north-western tip of the Cotentin (Cap de la Hague) and the island of Alderney (Channel Islands, UK) (Figure 3). The tidal currents running through this strait are among the strongest in Europe. At its northern extent, the Race extends over an area between 2 and 5 nautical miles wide, on a line joining the lighthouses of Mannez on Alderney and La Hague on the Cotentin. The Race is 
Citation: Foveau A, Haquin S, Dauvin J (2017) Using Underwater Imagery as a Complementary Tool for Benthos Sampling in an Area with High-Energy Hydrodynamic Conditions. J Mar Biol Oceanogr 6:2.

delimited in the south by a line between the Schôle bank and the Cap de Flamanville, to the West by a line between Mannez lighthouse and the Schôle bank and to the East by a line between from the Cap de Flamanville and the buoy 'Basse-Bréfort' (Figure 4). The water depth is comprised between 25 and $66 \mathrm{~m}$.
Current velocities and tidal range in the Alderney Race (Raz Blanchard) reach $8.5 \mathrm{knots}$ and $8 \mathrm{~m}$ during spring tide and this area is one the most promising area in the world for tidal power generation [22]. The local strength of the current is due to the acceleration of the tidal flow between the Alderney Island (Channel Islands) and La

Table 1: Number of pictures per stations (total number, number of images of the bottom, number of exploitable images).

\begin{tabular}{|l|l|l|l|l|}
\hline Campagne & Site & Total number & Bottom images & Exploitable images \\
\hline April 2016 & 1 & 71 & 21 & 19 \\
\hline April 2016 & 2 & 200 & 150 & 46 \\
\hline April 2016 & 3 & 205 & 165 & 40 \\
\hline April 2016 & 4 & 82 & 72 & 4 \\
\hline
\end{tabular}

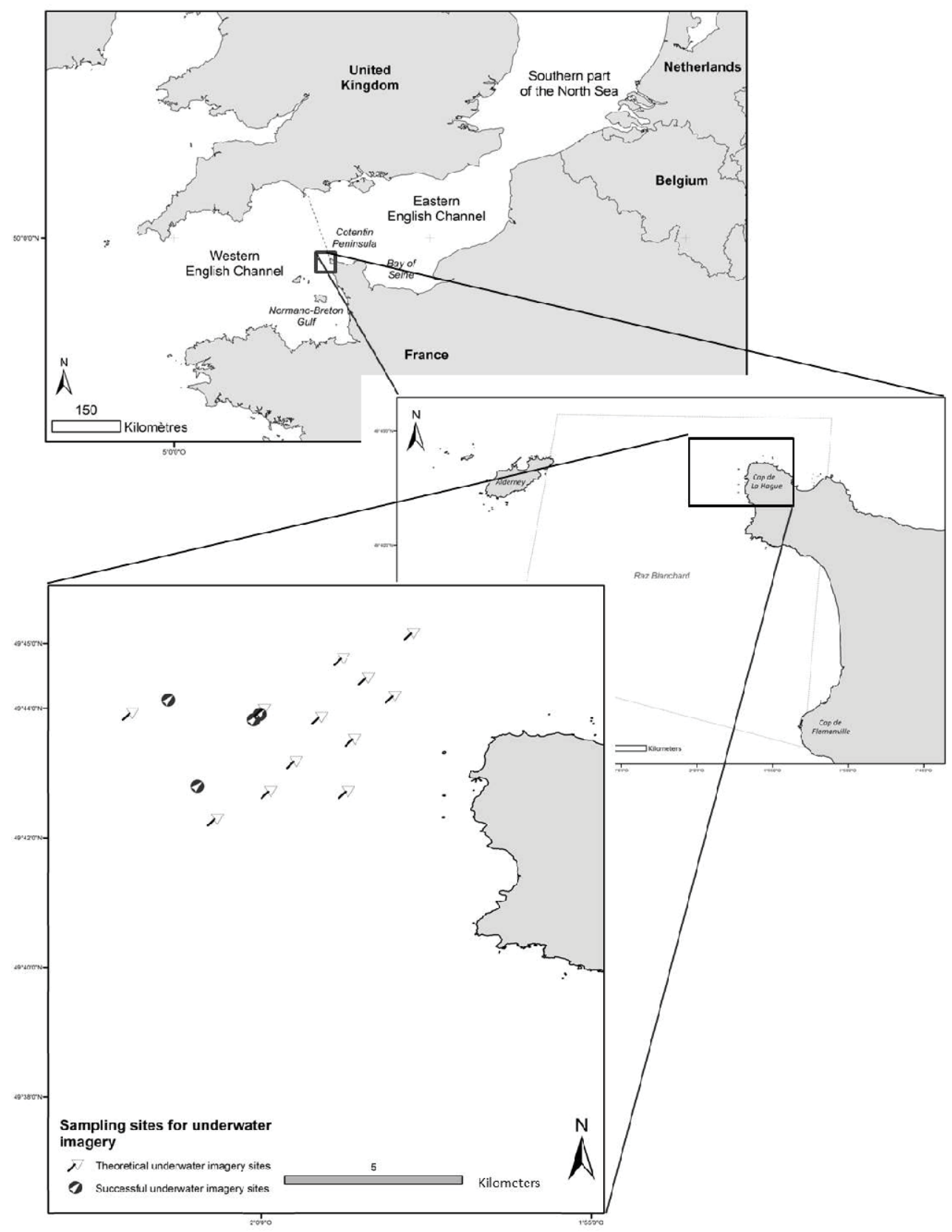

Figure 3: Sampling sites for underwater imagery in the Raz Blanchard area, in the Western part of the English Channel, Northeastern Atlantic. 
Citation: Foveau A, Haquin S, Dauvin J (2017) Using Underwater Imagery as a Complementary Tool for Benthos Sampling in an Area with High-Energy Hydrodynamic Conditions. J Mar Biol Oceanogr 6:2.

Hague Cap (France) [22].

The sea bed is complex, made up of a substratum composed of granite and calcareous rocks of Cambrian, Silurian and Cretaceous age $[23,24]$. The surficial sediments, where they exist, are formed of gravel and pebbles [24,25].

The primary survey took place in April 2016 and was conducted with the 'Marie-Catherine' professional fishing vessel in the Raz Blanchard, an area with small islets and numerous rocky shoals jutting out from an irregular seabed.

Because of this strongly irregular seabed (Figure 4), in some places with vertical depth variations of about $10 \mathrm{~m}$ over a distance of 5 $\mathrm{m}$, it was decided to investigate the bathymetry firstly with the vessel's sonar before deploying the sledge. Thus, only four stations exhibited a relatively flat surface on which the sledge could be used (Figure 3). The coordinates of the explored stations are presented on Table 2.

\section{Results}

The results obtained with our underwater imagery video system are essentially qualitative. Nevertheless, it permits to observe and describe the benthic seascapes in the Alderney Race which, as we remember, was a poorly understood area.

A total of 558 photos were obtained during the survey, $68 \%$ of which were taken on the seafloor (the other photos were taken during descent and ascent of the sledge, i.e. in the water column). Among these photos, only $38 \%$ were actually exploitable. Unfortunately, the strong bottom currents limited the quantity of the number of images. Indeed, the strength of the currents destabilized the fixations of the flash units, which led to unpredictable modifications of the viewing angle of the flash. This gave rise to many problems of exposure and sharpness on the photos. Owing to image processing software, it was possible to recover some of the photos but at the expense of a major degradation in their quality. This degradation of the image quality prevented us from correctly applying the methodology described above, or hindered their interpretation.

The exploitable images allow us to describe the type of sediments covering the seafloor. The significant sediments types are: (1) gravel and blocks, mixed together in a more or less cohesive way and (2) bedrock (Figure 5). It is also noteworthy that, in some places, fine sediments can be aggregated between coarser fragments. Another important observation is that relatively high turbidity levels are recorded in the area.

On these pictures (Figure 5), the presence of the following sessile fauna is noted: the barnacle Balanus crenatus, hydrozoans belonging to the genus Sertularia, as well as Porifera and Bryozoa.

Some of the hydroids could be measured, with the ImageJ freeware because our images were calibrated before sea surveys. We encountered size from 1.7 to $20.5 \mathrm{~cm}$, with a mean at $5.7 \mathrm{~cm}$ (Table 3 ).

\section{Discussion}

The underwater imagery sledge was designed to be used as a complementary tool applicable to pre-existing benthic monitoring

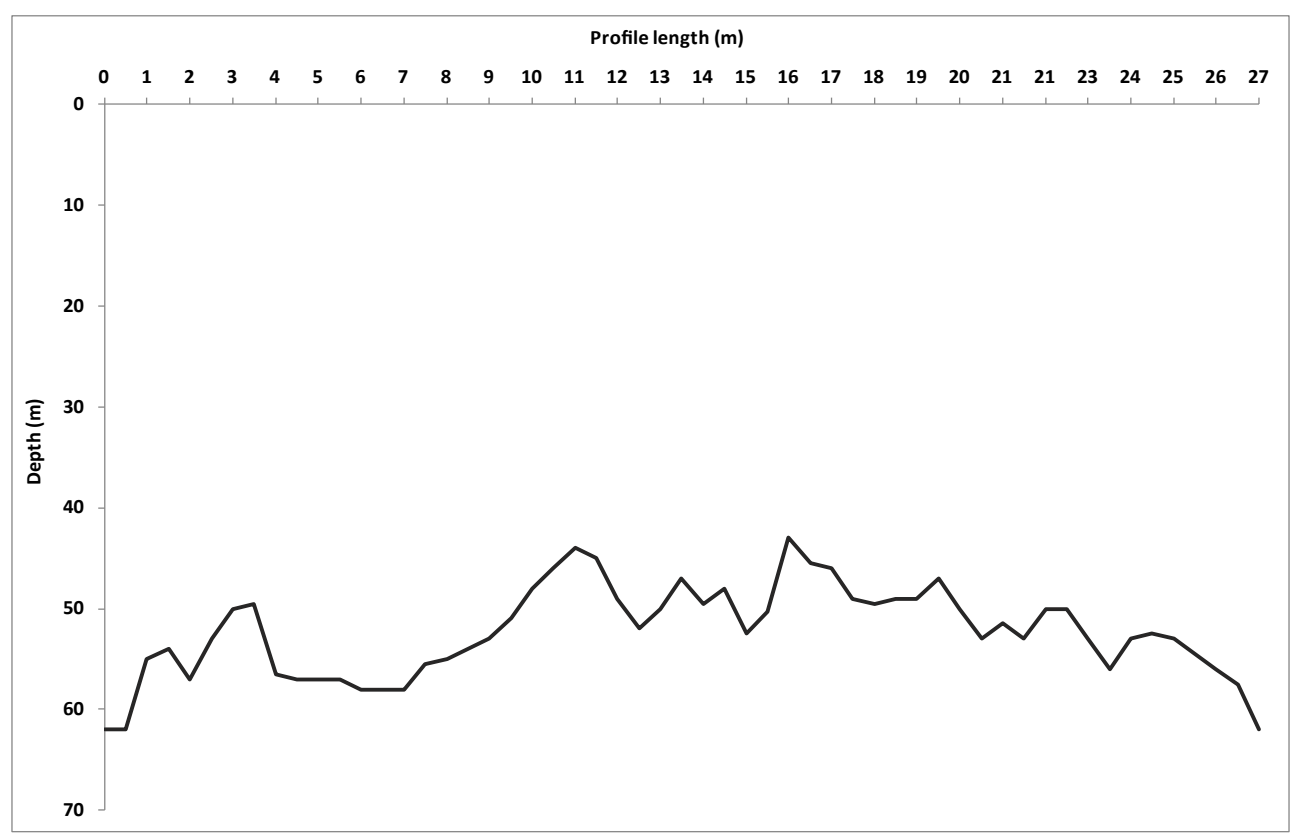

Figure 4: Typical profile of the sea bottom in the Raz Blanchard area, western part of the English Channel.

Table 2: Coordinates of the sampled stations and sediment types.

\begin{tabular}{|l|l|l|l|}
\hline Stations & Date & Mean Longitude & Mean Latitude \\
\hline 1 & $01 / 04 / 2016$ & -2.0018 & 49.730358335 \\
\hline 2 & $01 / 04 / 2016$ & -2.002 & 49.731725 \\
\hline 4 & $02 / 04 / 2016$ & -2.023308335 & 49.735433335 \\
\hline
\end{tabular}




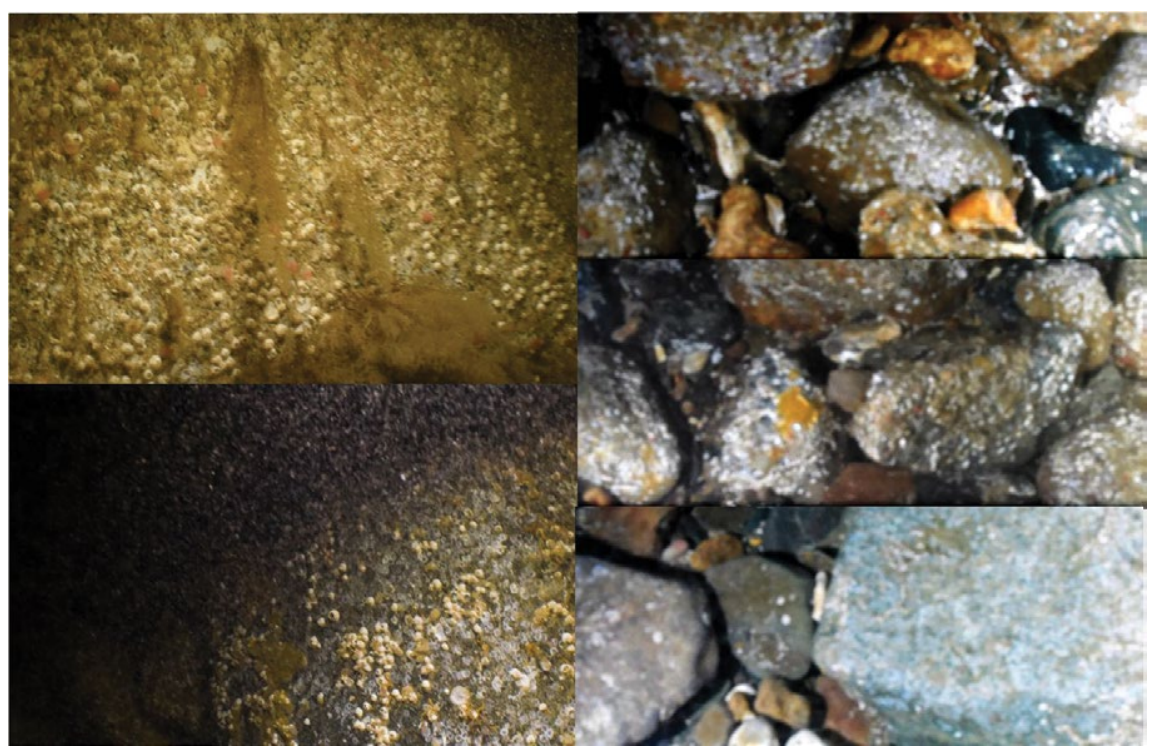

Figure 5: Selection of photos of the seafloor, with the presence of sessile fauna.

Table 3: Measurements of some specimens of Sertularia from images.

\begin{tabular}{|c|c|}
\hline Specimen & Size $(\mathbf{c m})$ \\
\hline 1 & 20.5 \\
\hline 2 & 10.1 \\
\hline 3 & 3.1 \\
\hline 4 & 1.7 \\
\hline 5 & 14.1 \\
\hline 6 & 8.6 \\
\hline 7 & 7.2 \\
\hline 8 & 11.8 \\
\hline 9 & 5.7 \\
\hline 10 & 6.9 \\
\hline 11 & 4.8 \\
\hline Mean & 5.8 \\
\hline
\end{tabular}

surveys. In fact, our system is a combination of both images (obtained with camera) which help to characterize sediments and fauna and videos (obtained with the movie camera) that help to characterize the seascapes.

A knowledge of the operating conditions during such surveys constrained the design of the sledge, which needs to be robust enough to be used over a wide range of depths, seabed types, currents velocities and weather conditions. This tool may be used safely, even under high-energy hydrodynamic conditions, as long as it is towed against the current.

This camera system is easy to use and deploy, even by a nonspecialized staff, and can be used on relatively small vessels. It would be useful at obtaining qualitative results on the macrofauna of an area, but has probably limited ability to describe 'vulnerable marine ecosystems', which are comprised of large megafauna such as corals and sponges, due to its low depth of view of the camera.

The first tests of this sledge revealed the necessity of using floats in the front of the frame to help its positioning in the water column during the down trip and ensure its balance on the seafloor. The position of the lights may be improved to avoid an artefact of bright halo on the photos. This frame is large enough to accommodate other types of sensors, such as CTD probes. Finally, the question of the accurate positioning of the videos to allow crossing with seabed morphometric layers is also particularly important. The addition of an underwater acoustic positioning device may be envisaged, although the cost of such piece of equipment is high and its use requires careful calibration on-board each ship. Another limitation of this gear is the no live link to the vessel during the deployment. The success of the operation can only be assessed after the retrieval of the system and in situations when adjustments are needed, it may constitute a loss of time at sea. However, the use of an optical cable, ideally also capable of powering and towing the sledge, at high depths was far too expensive and not in the initial specifications (gear easily repairable if broken). Moreover, an optical cable would be perhaps too fragile in such harsh environment than the Alderney Race.

The use of this equipment in a complex environment, such as the Raz Blanchard, requires taking precautions before launching the sledge. It is necessary to carry out depth sounding before data acquisition and to plot irregularities of the seafloor in order to avoid damage to the equipment. In these complex areas, it is also necessary to strengthen the structure of the tool and aid in its protection.

The main drawbacks for the data acquisition of underwater images in the Raz Blanchard stem from the very strong currents and the highly irregular seabed. We should also note that, although the currents are weaker at slack tide, which should allow more time for work, the time available is actually much shorter than in theory in the Alderney Race: slack tides in this area last for less than 15 minutes. The towing speed on the bottom is found to be optimal at around $1 \mathrm{knot}$ and is dependent on the depth and length of the cable used (the best images are obtained when the outgoing cables length is more than 3 times the sounded depth). But, we managed to operate our sledge with bottom currents up to 2.5 knots and to obtain exploitable images and in rough bottoms, because of the design of the sledge.

Particular attention should be paid to the sledge stability. Moreover, good lighting intensity and the use of HD resolution is considered to improve the power of the underwater imagery in taxonomic identification. The effect of resolution has already been highlighted by Soufflet [26], who compared analogue and HD 
Citation: Foveau A, Haquin S, Dauvin J (2017) Using Underwater Imagery as a Complementary Tool for Benthos Sampling in an Area with High-Energy Hydrodynamic Conditions. J Mar Biol Oceanogr 6:2.

cameras fixed on the same dropped system, concluding that, even with a smaller field of vision and poorer lighting, HD camcorders (1080p) yield better results than analogue cameras (720p).

Nevertheless, apart from these data acquisition problems, the heterogeneity of the seafloor in the Raz Blanchard is highlighted by the underwater images.

On the acquired images, it was not possible to observe mobile species, evidently due to their small size and infaunal life habits in such environmental conditions. Some relatively large sessile species could be observed, highlighting the three-dimensional distribution of the sessile fauna and their potential sheltering effect for the other species sampled by standard techniques.

The fauna collected with the Rallier du Baty dredge at these stations is dominated by sessile fauna and especially by Bryozoa Arthropoda is the dominant phylum represented in the mobile fauna. The sampled stations belong to the A4.13 EUNIS habitat type. The macrofauna is homogeneous at the scale of the study area and is comparable to the English Channel fauna found in the same bathymetric and sedimentary conditions. These observations are interestingly supplemented by data obtained with underwater imagery, particularly for the description of sessile epifauna and benthic landscapes.

This sledge system is sufficiently flexible, robust and simple to be used in coastal and offshore areas, to monitor the status and trends in seabed fauna as a complementary approach to conventional surveys of benthos using dredges and grabs permitting to describe the macrofauna assemblages and structural characteristic of the macrofauna (species richness, abundance and biomass). In the future, this system could be applicable to other monitoring or research programmes in the English Channel, such as the marine renewable energy (offshore wind or turbine farms) or for the effect of marine aggregate extraction on the sea floor integrity and impact on the macrobenthic communities.

\section{Acknowledgments}

The authors are grateful to the crews of the 'Celtic Warrior' and the 'MarieCatherine' for their help in sampling operations. The results are derived from the PILE \& TIDE project, funded by the ADEME in the framework of the programme "Energies décarbonées des investissements du futur"; the authors thanks their colleague A.C. Bennis for her laboratory coordination. The authors also thank M.S.N. Carpenter for the English revision.

\section{Reference}

1. Boutan L (1893) Mémoire sur la photographie sous-marine. Arch Zool Exp Génér 3: 281-324.

2. Solan M, Germano JD, Rhoads DC, Smith C, Michaud E, et al. (2003) Towards a greater understanding of pattern, scale and process in marine benthic systems: a picture is worth a thousand worms. J Exp Mar Biol Ecol 285: 313-338.

3. Shortis M, Harvey E, Seager J (2007) A Review of the Status and Trends in Underwater Videometric Measurement. SPIE Conference 6491: 1- 26.

4. Mallet D, Pelletier D (2014) Underwater video techniques for observing coastal marine biodiversity: A review of sixty years of publications (19522012) Fish Res 154: 44-62.

5. Larocque R, Thorne M (2012) Benthic Optical Imagery in the Estuary and Gulf of St. Lawrence: Methods and Projects Directory, 1999-2012. Canadian Technical Report on Fisheries and Aquatic Sciences, Canada 3017: 40.

6. Fabri MC, Pedel L, Beuck L, Galgani F, Hebbeln D, et al. (2014) Megafauna of vulnerable marine ecosystems in French mediterranean submarine canyons: Spatial distribution and anthropogenic impacts. Deep Sea Res Part II: Topic Stud Oceanogr 104: 184-207.

7. Sheehan EV, Vaz S, Pettifer E, Foster NL, Nancollas SJ, et al. (2016) An experimental comparison of three towed underwater video systems using species metrics, benthic impact and performance. Meth Ecol Evol 7: 843-852.
8. Manchan R, Fedra K (1975) A new towed underwater camera system for wide-range benthic surveys. Mar Biol 33: 75-84.

9. Patterson KR (1984) Distribution patterns of some epifauna in the Irish Sea and their ecological interactions. Mar Biol 83: 103-108.

10. Hughes DJ, Atkinson RJA (1997) A towed video survey of megafaunal bioturbation in the north-eastern Irish Sea. J Mar Biol Assoc UK 77: 635-653.

11. Rosenkranz GE, Byersdorfer SC (2004) Video scallop survey in the eastern Gulf of Alaska, USA. Fish Res 69: 131-140.

12. Watanabe T (2002) Method to estimate the population density of the snow crab Chionoecetes opilio using a deep-sea video monitoring system on a towed sledge. Japan Agricul Res Quart 36: 51-57.

13. Spencer ML, Stoner AW, Ryer CH, Munk JE (2005) A towed camera sled for estimating abundance of juvenile flatfishes and habitat characteristics: comparison with beam trawls and divers. Estuar Coast Shelf Sci 64: 497-503.

14. Stoner AW, Spencer ML, Ryer CH (2007) Flatfish-habitat associations in Alaska nursery grounds: Use of continuous video records for multi-scale spatial analysis. J Sea Res 57: 137-150.

15. Shucksmith R, Hinz H, Bergmann I, Kaiser MJ (2006) Evaluation of habitat use by adult plaice (Pleuronectes platessa $\mathrm{L}$.) using underwater video survey techniques. J Sea Res 56: 317-328.

16. Carbines G, Cole RG (2009) Using a remote drift underwater video (DUV) to examine dredge impacts on demersal fishes and benthic habitat complexity in Foveaux Strait, Southern New Zealand. Fish Res 96: 230-237.

17. Smith C, Banks A, Papadopoulou K (2007) Improving the quantitative estimation of trawling impacts from sidescan-sonar and underwater-video imagery. ICES J Mar Sci 64: 1692-1701.

18. O'Neill F, Summerbell K, Breen M (2009) An underwater laser stripe seabed profiler to measure the physical impact of towed gear components on the seabed. Fish Res 99: 234-238.

19. Tessier A, Pastor J, Francour P, Saragoni G, Crechriou R, et al. (2013) Video transect as a complement to underwater visual census to study reserve effect on fish assemblages. Aquat Biol 18: 229-241.

20. Retière C (1979) Contribution to the study of benthic stands of the NormanoBreton Gulf. PhD Thesis, ès Sciences Naturelles, University of Rennes, Rennes, France.

21. Broadhurst $M(2013)$ The ecology of marine tidal race environments and the impact of tidal energy development. PhD Thesis, Imperial College London, United Kingdom, $224 \mathrm{p}$.

22. Thiébot J, Bailly du Bois $P$, Guillou $S$ (2015) Numerical modeling of the effect of tidal stream turbines on the hydrodynamics and the sediment transportApplication to the Alderney Race (Raz Blanchard), France. Renew Energy 75: 356-365.

23. Boillot G (1964) Geology of the Western Channel: rocky bottoms, quaternary deposits, current sediments. Annal Inst Océanogr Paris 42:1-219.

24. Hommeril P (1967) Study of marine geology concerning the Lower Normandy coastline and the pre-littoral zone of the Anglo-Norman archipelago. PhD Thesis, University of Caen, France.

25. Larsonneur C, Bouysse P, Auffret JP (1982) The superficial sediments of the English Channel and its western approaches. Sedimentology 29: 851-864.

26. Soufflet $M$ (2013) Comparison of benthic megafauna assemblages from observations by bottom trawl and underwater video. Report of Master 1 Université Lille1, France.

\section{Author Affiliations}

${ }^{1}$ Normandie Univ., UNICAEN, UNIROUEN, Université de Caen Normandie, Laboratoire de Morphodynamique Continentale et Côtière, UMR CNRS 6143 M2C, 24 rue des Tilleuls, F-14000 Caen, France

2Ifremer, Laboratoire Environnement Ressources Bretagne Nord, 38 Rue du Port Blanc, F-35800 Dinard, France

${ }^{3}$ Ecole centrale de Nantes, UMR 6598 Laboratoire De Recherche En Hydrodynamique, Energétique Et Environnement Atmosphérique (LHEEA), 1 Rue de la Noé, BP 92101, F-44321 Nantes Cedex 3, France 